\title{
Prediction of slurry erosive wear behaviour of Al6061 alloy using a fuzzy logic approach
}

\author{
C. S. Ramesh ${ }^{1,3}$, V. K. S. Jain ${ }^{1}$, R. Keshavamurthy ${ }^{2}$, Z. A. Khan ${ }^{3}$ \\ \& M. Hadfield ${ }^{3}$ \\ ${ }^{1}$ Department of Mechanical Engineering, \\ PES Institute of Technology, Bangalore, India \\ ${ }^{2}$ Central Manufacturing Technology Institute, Bangalore, India \\ ${ }^{3}$ School of Design, Engineering and Computing, \\ Bournemouth University, UK
}

\begin{abstract}
Slurry erosive wear as a failure mechanism has significance in terms of dictating the performance of marine components. Experimental determination of this wear phenomenon for various materials in current naval applications is tedious, expensive and, in the majority of cases, not reliable. The standard experimental procedures in assessing the slurry erosive wear do not simulate the actual operating conditions. Researchers have been focusing on predictions of wear behaviour based on several hypotheses and mathematical models as a response to overcome the above mentioned obstacles. The fuzzy logic approach is a highly reliable analytical technique and therefore widely accepted and used.

This paper discusses a fuzzy logic model to predict the slurry erosive wear behavior of cast aluminum 6061 (Al 6061) alloy pre and post heat treatment. The adopted fuzzy model employs hybrid-learning techniques involving a combination of both back-propagation and least-square method. Sand concentration, test duration, slurry rotation speed and impinging particle sizes served as inputs while slurry erosive wear losses were the outputs. The predicted values have been compared with published experimental data under various operating conditions. The predicted values of slurry erosive wear loss of cast aluminum 6061 alloy pre and post heat treatment are in close agreement with the experimental results.
\end{abstract}

Keyword: fuzzy logic, Al6061, slurry erosive wear. 


\section{Introduction}

In recent years, the use of aluminum and its alloys has significantly increased in several engineering applications, such as: marine, aerospace, automobile and chemical industries. Structural integrity and durability suffers from corrosion related deterioration in conventional materials [1-3]. Aluminum offers high strength to weight ratio, excellent corrosion resistance coupled with enhanced surface finish characteristics [4].

However, these alloys in many afore- mentioned engineering sectors do result in severe wear leading to maintenance, durability and reliability associated issues. These issues bring health and safety and financial implications. In addition the presence of aggressive corrosive media especially in industries such as slurry handling plants will accelerate the component wear leading to catastrophic failures [5]. Hence, serious attempts have been made by researchers to focus on the experimental determination of different modes of wear with regard to aluminum and its alloys under several operating conditions using standard test procedures [6-9]. However, these standard techniques for assessing their wear properties are sometimes complex and may not simulate the actual working operating conditions leading to spurious and unrealistic data. There is a need to generate reliable test database to assess the suitability of the developed alloys with optimized wear resistant properties for specific applications. This process is quite long and tedious. To address this problem researchers have focused on prediction of wear properties of aluminum alloys using various analytical approaches. Ramesh et al. have reported the prediction of adhesive wear behavior of Al6061 based composites using Yang and Archard models with 1 to $7 \%$ error range [10]. Hassan et al. have proposed a model for evaluation and prediction of slurry erosion wear loss of 5127 steels with error ranging from +14 to $-7 \%$ [11]. These analytical models do emphasize on individual effect of design factors rather than the holistic approach of the wear phenomenon. This limits the accuracy in predictions from these models; hence, with the advances in computing techniques, researchers are now exploiting fuzzy logic tools for accurate predictions of various phenomena in different applications that include material science, tribology, aerospace, and automotive [10-15]. Fuzzy logic model can build nonlinear functions of arbitrary complexity based on experience of experts and are flexible to design the control system [16].

However, no information is available to predict wear behavior of aluminum and its alloys by fuzzy logic approach. Current research focuses on the use of appropriate fuzzy model to predict the slurry erosion wear behavior of cast Al6061, which is the most, sought after material for many of the marine and slurry handling components.

\section{Experimental details}

Slurry erosion tests were carried out as per ASTM G75-07 standard on polished samples of size $8 \mathrm{~mm}$ thick, $8 \mathrm{~mm}$ width and $40 \mathrm{~mm}$ length. The samples were thoroughly cleaned in acetone and weighed using an electronic microbalance 
before and after the wear test. The accuracy of electronic balance was $10^{-1} \mathrm{mg}$. The details of the test set up and complete experimental procedure is described in our earlier published work [4].

\section{Methodologies}

\subsection{Architecture of Adaptive Neuro Fuzzy Inference System (ANFIS)}

ANFIS is a type of neural network that is based on Takagi-Sugeno fuzzy inference system. In this work, ANFIS architecture is being adopted owing to its unique advantages. It computes the membership function parameters that best allow the associated fuzzy inference system to track the input/output data. Two techniques in ANFIS are adopted in updating the member parameters resulting in the fine tuning of variable parameters that define the membership functions. One such is gradient descent and the other is least square methods. However, in this work, the hybrid technique of learning which is a combination of the gradient descent method and the least-squares method is being used because of its several advantages. The flow chart of hybrid learning procedure for ANFIS is shown in Fig. 1 [14]. During training in ANFIS, 65 sets of experimental data of slurry erosive wear loss of cast Al6061 alloy before and after heat treatment and remaining sets of experimental data are taken as testing data to check accuracy of fuzzy logic which comes nearer to 95-98\% when compared to experimental ones have been used to conduct 500 cycles of learning.

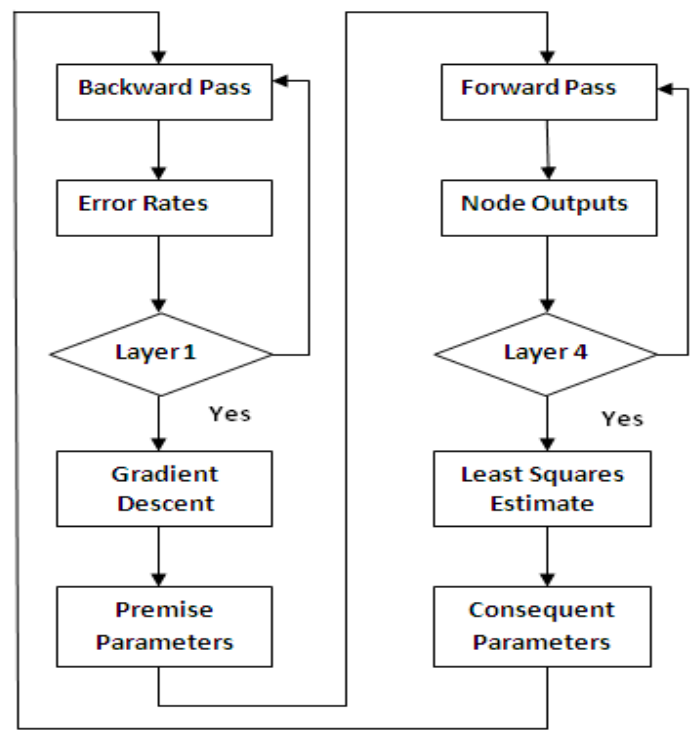

Figure 1: $\quad$ Flow chart of hybrid learning process. 


\subsection{Fuzzy Inference System (FIS)}

The ANFIS model was developed using Matlab fuzzy logic tool. A fuzzy inference system (FIS) essentially defines a nonlinear mapping of the input data vector into a scalar output, using fuzzy rules. The mapping process involves input/output membership functions, FL operators, fuzzy if-then rules, aggregation of output sets, and defuzzification. A block diagram of a fuzzy inference system (FIS) is shown in Fig. 2. It consist of four components namely fuzzifier, inference engine, rule base and defuzzifier.



Figure 2: $\quad$ Block diagram of fuzzy inference system.

Fuzzification stage is used to convert the measured quantities (sand concentration, test duration, slurry rotation speed and impinging particle sizes) from the process into fuzzy sets to be used by the inference stage. However if there is a process or measurement noise, it is accounted by creating fuzzy sets for the measured quantities. In the second step, inference engine defines mapping from input fuzzy sets into output fuzzy sets, which determines the degree to which the antecedent is satisfied for each rule. If the antecedent of a given rule has more than one clause, fuzzy operators are applied to obtain one numeric value that represents the result of the antecedent for that rule. Possibilities are that one or more rules may fire simultaneously. Outputs for all the rules are then aggregated. The rule base contains linguistic rules that are provided by experts or extracting rules from numeric data. In the present work, the linguistic rules are formulated based on the available numerical data. Slurry erosive wear depends on several parameters such as hardness of the materials, erosive particle type, size and shape, concentration of erosive particles in the slurry and rotational speed. A total of 128 appropriate linguistic rules based on the conditions are created such as IF, AND, THEN statements which can be obtained through appropriate relations. The present work has made use of the relations such as very -very low, very low, medium, high, very high, very-very high.

Once the rules have been established, the FIS can be viewed as a system that maps an input vector such as sand concentration, test duration, slurry rotation speed and impinging particle sizes to an output slurry erosive wear vector. The 
fuzzifier maps input numbers into corresponding fuzzy memberships in order to activate the rules that are in terms of linguistic variables [17].

Defuzzification maps the output fuzzy sets into a definite number. Several common methods for defuzzification in practice includes the centroid, maximum, mean of maxima, height and modified height defuzzifier. The centroid method of defuzzification method is been adopted in this work which calculates and returns the center of gravity of the aggregated fuzzy set. Modelling of slurry erosive wear has been performed by using fuzzy model considering four input parameters and one output parameter. The four input parameters are sand concentration, particle size, time duration and rotational speed as reported in Table 1 while the output is slurry erosive wear in terms of weight loss. A schematic block diagram of the adopted FIS is shown in Fig. 2.

Table 1: $\quad$ The input parameters.

\begin{tabular}{|c|c|c|c|}
\hline Sand Concentration(g/ltr) & Particle Size $(\mu \mathrm{m})$ & $\begin{array}{c}\text { Time } \\
\text { Duration(hrs) }\end{array}$ & Speed(rpm) \\
\hline $100-400$ & $106-625$ & $5-25$ & $500-1500$ \\
\hline
\end{tabular}

\section{Results and discussion}

\subsection{Effect of slurry concentration and test time}

Fig. 3 shows the combined effects of slurry concentration and test time on both the predicted and experimental slurry erosive wear loss of unheat treated and heat treated cast Al6061alloy. It is observed that the mass loss of unheat treated and heat treated cast Al6061 alloy increases with increase in both test time (up to 20hrs) and slurry concentration (up to $250 \mathrm{~g} / \mathrm{litre}$ ) with other parameters being constant at their average values. A maximum of $0.2275 \mathrm{~g}$ (experimental) and 0.2281g (predicted) mass loss are observed for unheat treated cast Al6061 alloy. The increased slurry erosive mass loss with increase in slurry concentration and test duration can be attributed to the following reasons. 1) Increased concentration of sand results in more abrasive action, enhancing the probability of the material removal by ploughing and micro cutting. 2) Increase in test duration results in more corrosive attack of the alloy due to presence of $\mathrm{NaCl}$ in slurry leading to material removal due to combined process of erosion and corrosion. The decrease in mass loss is observed beyond slurry concentration of $250 \mathrm{~g} / \mathrm{l}$ and test duration of 20hrs, which can be attributed to the following reasons. 1) Very high sand concentration at a given rotational speed results in lowering of impinging velocity of the abrasive sand particles, which in turn reduces the extent of surface damage. 2) Very high-test durations for a given slurry concentration and rotational speed leads to fragmentation of the abrasive silica particles losing its sharp edges. This phenomenon results in lowering the erosion effect. However for a given test duration and slurry concentration, ice quenched Al6061 possess minimum weight loss of 0.1696g (experimental) and 0.1725 g (predicted) when compared with air and water quenched heat treated 


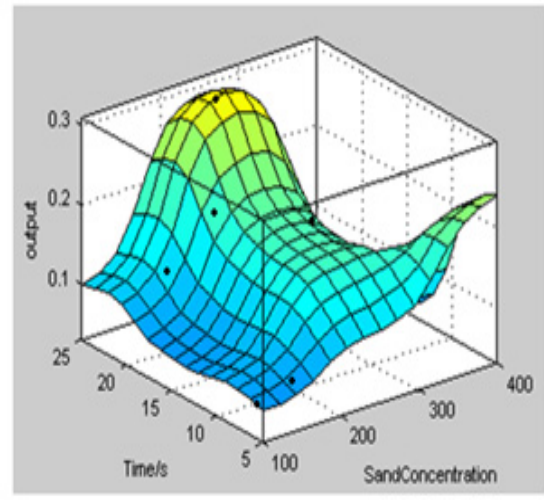

(A) Unheat treated

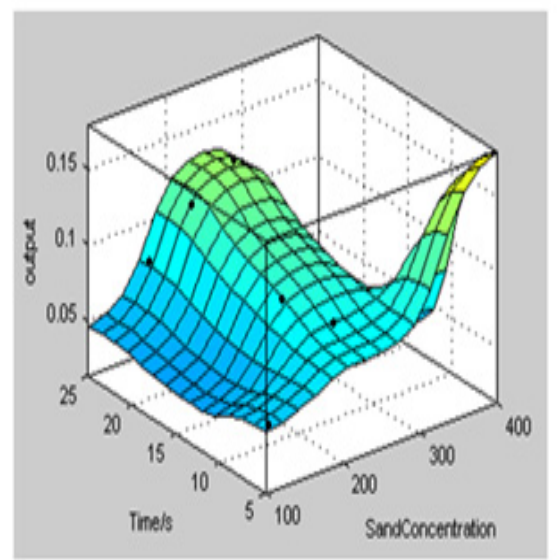

(C) Water quenched

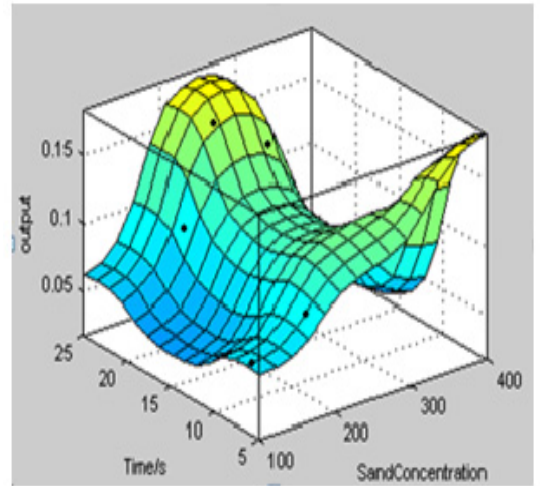

(B) Air quenched

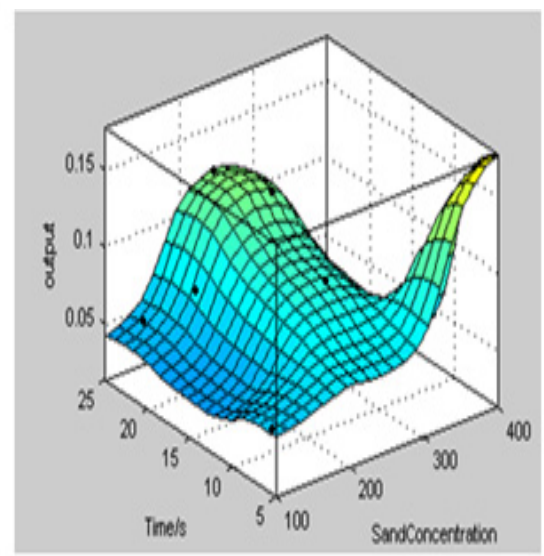

(D) Ice quenched

Figure 3: 3D surface plot of slurry erosive wear (mass loss) v/s sand concentration and test time for unheat treated and heat treated conditions. (Dots represent experimental data.)

alloys. For any given slurry concentration and test duration, the predicted mass loss from the developed fuzzy model matches closely with the experimental ones. The average error between the experimental and the predicted slurry erosive mass loss ranges between 1 and $3 \%$.

\subsection{Effect of impinging particle size and slurry concentration}

Fig. 4 shows the combined effect of impinging particle size and slurry concentration on both predicted and experimental erosive wear loss of unheat treated and heat treated cast Al6061alloy. It is observed that increase in the particle size and sand concentration results in increase in mass loss for both unheat treated and heat treated cast Al6061 alloy. For a sand particle size of $300 \mu \mathrm{m}$ with slurry concentration maximum mass loss of $250 \mathrm{~g} / \mathrm{l}$ has been 
observed. A maximum of 0.1481 g (experimental) and $0.1497 \mathrm{~g}$ (predicted) mass loss are observed for unheat treated cast Al6061 alloy. However, ice quenched Al6061 alloy exhibit minimal slurry erosive wear loss among all studied quenching media for all the particle size and slurry concentration under investigation. The average error between the experimental and predicted slurry erosive mass loss ranges between 1 and 3.5\%. Increase in slurry erosive wear loss with increase in particle size can be attributed to increase in surface area. Larger surface contact area leads to increased levels of stresses both at surface and sub surface levels. This contributes to higher plastic deformation which is one of the important mechanisms for material removal during slurry erosion process.

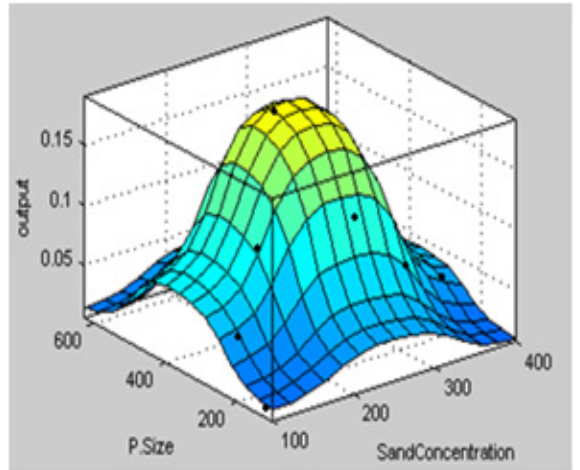

(A) Unheat treated

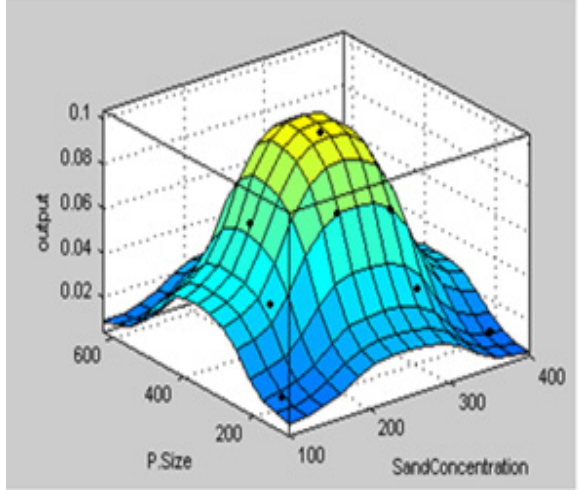

(C) Water quenched

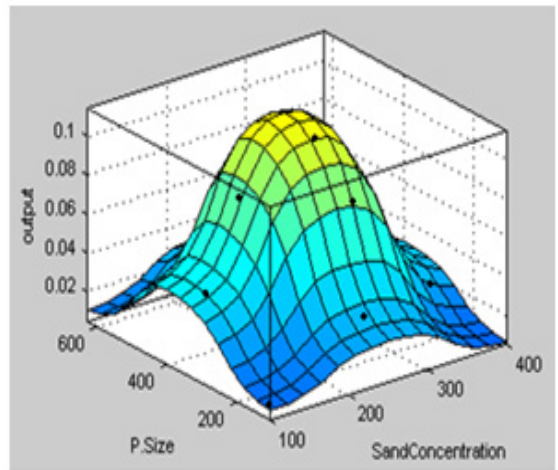

(B) Air quenched

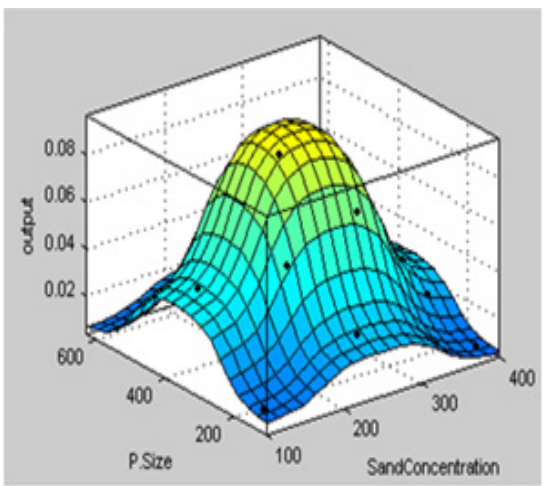

(D) Ice quenched

Figure 4: 3D surface plot of slurry erosive wear loss (mass loss) v/s sand concentration and impinging particle size for unheat treated and heat treated condition (Dots represents experimental data).

\subsection{Effect of test time duration and speed of slurry rotation}

Fig. 5 shows variations of predicted slurry erosive wear loss for different slurry rotational speeds and test durations. It is observed that increasing the test 
duration and speed of slurry rotation results in increased mass loss for both unheat treated and heat treated cast Al6061 alloy. It is observed that increase in the slurry rotation speed and test duration results in increased mass loss for both unheat treated and heat treated cast Al6061 alloy. Maximum mass loss is observed at a slurry rotational speed of $1200 \mathrm{rpm}$ with the test duration of $22 \mathrm{hrs}$. Increase in slurry erosive mass loss with increased slurry rotational speed. This is attributed to increased kinetic energy of the abrasive sand particles. Increased kinetic energy of the abrasive particles results in their enhanced collisions with the targeted alloy surface. Larger the probability of collisions, higher will be the extent of surface damage of the targeted alloy leading to increased levels of wear.

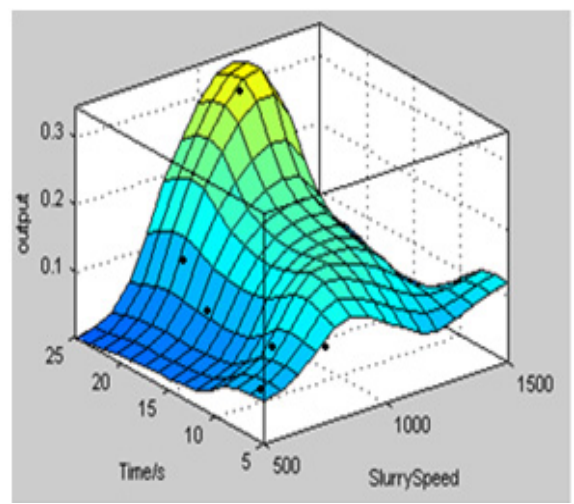

(A) Unheat treated

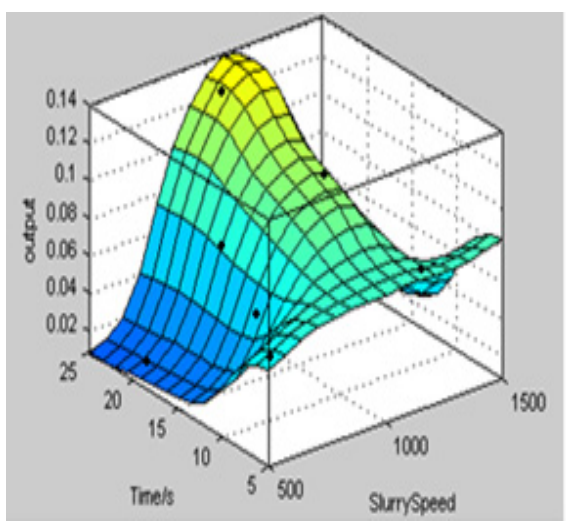

(C) Water quenched

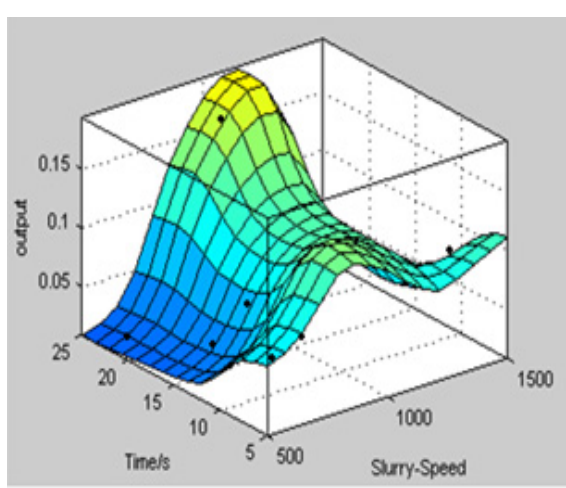

(B) Air quenched

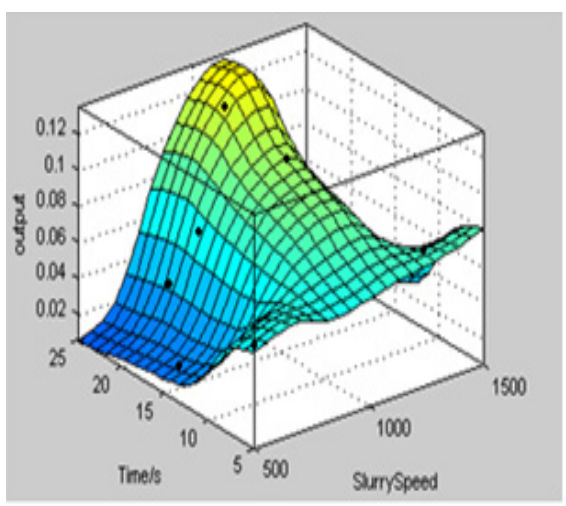

(D) Ice quenched

Figure 5: 3D surface plot of slurry erosive wear loss (mass loss) v/s test time and speed of slurry rotation for unheat treated and heat treated condition (Dots represents experimental data). 
The average minimum and maximum errors between experimental and predicted results are found to be $2 \%$ and $5 \%$ respectively. However ice quenched Al6061 alloy do exhibit minimal slurry erosive mass loss at all the test durations and slurry rotational speed with all other parameters such as impinging particle size and sand concentration being maintained constant at their average values.

\subsection{Effect of speed of slurry rotation and impinging particle size}

Fig. 6 shows the combined effects of impinging particle size and slurry rotational speeds on both predicted and experimental erosive mass loss of unheat treated and heat treated cast Al6061 alloy. It is observed that increasing the particle size

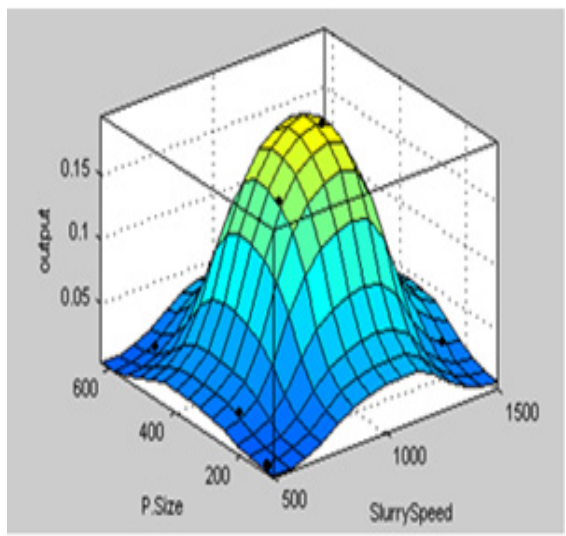

(A) Unheat treated

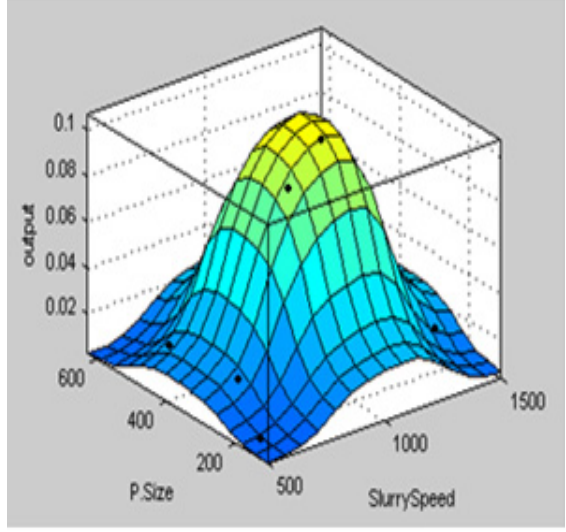

(C) Water quenched

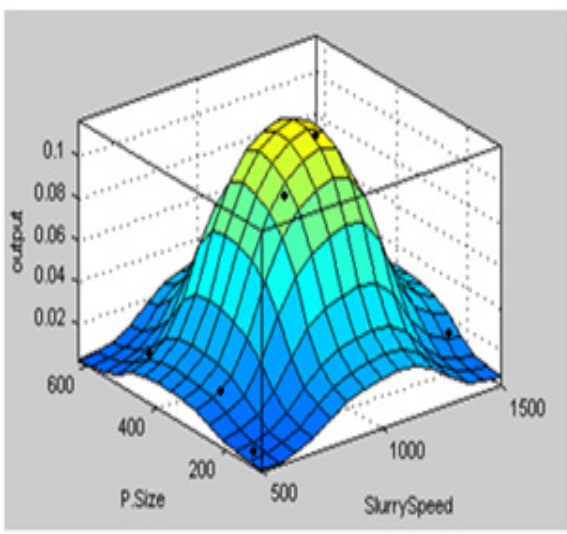

(B) Air quenched

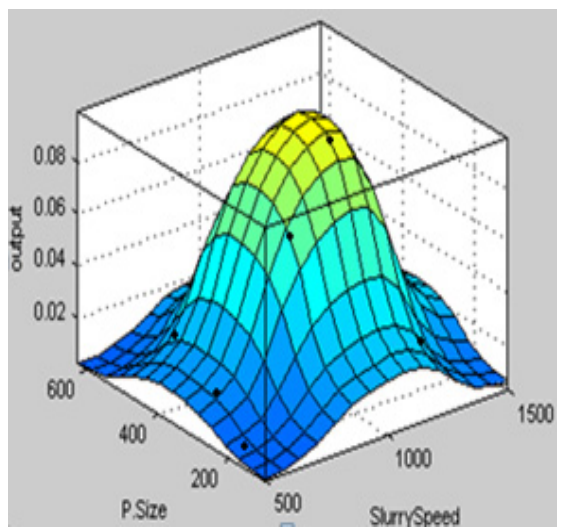

(D) Ice quenched

Figure 6: 3D surface plot of slurry erosive wear loss (mass loss) v/s impinging particle size and speed of slurry rotation for unheat treated and heat treated condition (Dots represents experimental data). 
and speed of slurry rotation results in increased mass loss for both unheat treated and heat treated cast Al6061 alloy. Maximum weight loss is observed for a slurry rotational speed of $1200 \mathrm{rpm}$ and particle size of $400 \mu \mathrm{m}$.

The minimum and maximum experimental slurry erosive wear losses are $0.0483 \mathrm{~g}$ and $0.1019 \mathrm{~g}$ respectively. The minimum and maximum predicted slurry erosive wear losses are $0.0488 \mathrm{~g}$ and $0.1025 \mathrm{~g}$ respectively. The error between the experiments and the predicted slurry erosive wear loss ranges between 1-4\%. However ice quenched Al6061 alloy do exhibit minimum slurry erosive wear loss at all particle sizes and slurry rotational speeds with other parameters such as test time durations and sand concentration being maintained constant at their average values. The excellent slurry erosive wear resistance under all test conditions investigate for heat treated Al6061 alloys are mainly attributed to the following reasons. 1) Improved hardness on solutionizing and quenching followed by artificial aging. 2) Grain size reduction on heat treatment. Ice quenching do result in maximum improvement of hardness as well grain size reduction leading to superior slurry erosion wear resistance.

\section{Conclusions}

An appropriate fuzzy model has been developed to predict the slurry erosive wear loss of cast Al6061 alloy pre and post heat treatment. The predicted results are in close agreement with experimental results. It has been observed that at all sand concentration, impinging particle size, slurry rotation speed and time ice quenched Al6061 demonstrated least slurry erosion wear loss when compared with air, water quenched and unheatreated cast Al6061 alloy. Maximum slurry erosive wear loss of cast Al6061 alloy as predicted and experimentally observed occurs at a sand concentration of $250 \mathrm{~g} / \mathrm{l}$, slurry rotational speed of $1200 \mathrm{rpm}$, test duration of $20-22 \mathrm{hrs}$ and particle size of 300 $400 \mu \mathrm{m}$.

\section{References}

[1] Dobson, P., Khan, Z., Design considerations for carbon steel pipes materials' selection applied in fossil powered plants subjected to wet-steam flow accelerated corrosion: review paper. Journal of Corrosion Science and Engineering, 16, 1-13. 2013 Retrieved from http://www.scopus.com/source /sourceInfo.url?sourceId=12326\&amp;origin=recordpage

[2] Saeed, A., Khan, Z., Hadfield, M., and Davies, S. (2013). Material Characterisation and Real Time Wear Evaluation of Pistons and Cylinderliners of the Tiger 131 Military Tank. Tribology Transactions. doi:10.1080/10402004.2013.771416.

[3] Saeed, A., Khan, Z., and Montgomery, E. L. (2013). Corrosion Damage Analysis and Material Characterization of Sherman and Centaur - The Historic Military Tanks. Materials Performance and Characterization, 2(1), 1-16. doi:10.1520/MPC20120016. 
[4] Ramesh, C.S., Keshavamurthy, R., Channabasappa, B.H., Pramod. S., Influence of heat treatment on slurry erosive wear resistance of Al6061 Alloy. Materials \& Design, 30, pp. 3713-3722, 2009.

[5] Ramesh, C.S., Keshavamurthy, R., Slurry erosive wear behavior of Ni-P coated $\mathrm{Si}_{3} \mathrm{~N}_{4}$ reinforced Al6061 composites. Materials \& Design, 32, pp. 1833-1843, 2011.

[6] Aminul Islam, Md., Mohar Ali Bepari, Md., Shorowordi, Kazi Md., Dry sliding wear in case-hardened niobium micro alloyed steels. Journal of Materials Processing Technology, 160, pp. 401-409, 2005.

[7] Ramesh, C.S., Seshadri, S.K., Iyer, K.J.L., A Survey of Aspects of Wear of Metals. Indian J. Technol, 29, pp. 179-185, 1991.

[8] Ramesh, C.S., Keshavamurthy, R., Pramod, S., Koppad Praveennath G., Abrasive wear behavior of $\mathrm{Ni}-\mathrm{P}$ coated $\mathrm{Si}_{3} \mathrm{~N}_{4}$ reinforced Al6061 composites. Journal of Materials Processing Technology, 211, pp. 14231431, 2011.

[9] Muratoglu, M., Aksoy, M., Abrasive wear of 2124Al-SiC composites in the temperature range $20-200^{\circ} \mathrm{C}$. Journal of Materials Processing Technology, 174, pp. 272-276, 2006.

[10] Ramesh, C.S., Abrar Ahamed., Prediction of wear coefficient of Al6063$\mathrm{TiB}_{2}$ in situ composites. Proc of National Tribology Conf, Roorke, India, pp. 1-4, 2011.

[11] Hassan, M.A., Elsharief, M.A., Aboul Kasem, A., Ramesh, S., Purbolaksono, J., A fuzzy model for evaluation and prediction of slurry erosion of 5127 steels. Materials \& Design, 39, pp. 186-191, 2012.

[12] Blake, Y., Sliding wear prediction of ductile materials. Journal of Materials Processing Technology, 118, pp. 205-211, 2001.

[13] Anil Gupta, Hari Singh, Aman Aggarwal, Taguchi-fuzzy multi output optimization (MOO) in high speed CNC turning of AISI P-20 tool steel. Expert Systems with Applications, 38, pp. 6822-6828, 2011.

[14] Yu-Sen. Yang, and Wesley Huang, A grey-fuzzy Taguchi approach for optimizing multi-objective properties of zirconium-containing diamond-like carbon coatings. Expert Systems with Applications, 39, pp. 743-750, 2012.

[15] Zuperl Uros, Cus Franc, Kiker Edi, Adaptive network based inference system for estimation of flank wear in end-milling. Journal of Materials Processing Technology, 209, pp. 1504-1511, 2009.

[16] Jyh-Shing Roger Jang, Adaptive-network-based fuzzy inference system. IEE Transactions on System, Man and Cybernetics, 23, pp. 665-685, 1993.

[17] Fuzzy logic toolbox for use with Matlab user's guide Ver. 2.0 2010. 